\title{
Computational Study of Coal Particle Distribution in Coal Pulverizer: Effect of Air Flow Rate and Coal Particle Flow Rate
}

\author{
Elaine Why ${ }^{1,}$, Firas Alnaimi $^{1}$, Hasril Hasini ${ }^{1}$ and Mohammad Nasif ${ }^{2}$ \\ ${ }^{1}$ Power Generation Unit, Institute of Power Engineering (IPE), Universiti Tenaga Nasional, 43000 \\ Kajang, Selangor, Malaysia. \\ ${ }^{2}$ Mechanical Engineering Department, Universiti Teknologi Petronas, 32610 Tronoh, Malaysia.
}

\begin{abstract}
Complete combustion of coal fuel in thermal power plant is often achieved, by ensuring output of fine coal particle $(<75 \mu \mathrm{m})$ is as high as possible. This is due to the fact that same mass of coal particle in smaller sizes, has higher surface exposed to combustion. Hence, the objective of the study is to determine the effect of air flow rate and coal particle flow rate on coal fineness output. Computational fluid dynamics (CFD) modelling and validation with experimental coal fineness test in real plant are made. The optimum range of air flow rate and coal particle flow rate in pulverizer are selected, by considering relevant air/fuel ratio of 1.5 to 2.0 and turbulence intensity.
\end{abstract}

\section{Introduction and background}

Thermal power plant contributes the major percentage of electricity supply to grid in Malaysia, and acts as base load power plant due to its consistency in long term power generation. Firstly, coal as the major fuel to the plant will be processed through pulverization and classification into desired sizes. Next, the classified coal powder will be transported to combustion chamber by pneumatic conveying of primary air. Finally, the coal powder is then combusted by mixing it with hot air, in order to form fireball for steam generation in boiler [1]. However, incomplete combustion of coal fuel due to output of coarse sizes from pulverizer, will result in excessive waste emission of unburned carbon and ashes. Therefore, maintaining an optimum fineness of coal fuel output is important, in order to sustain clean environment and prolong smooth operation of plant.

A series of CFD related published works is reviewed, which focuses on the effect of different flow rate of air and coal dust in separation devices. Effect of particle flow rate in dust separation devices were investigated by G. Wan et al. and K. W. Chu et al. [2-5]. G. Wan et al. stated that the increasing of particle mass flow rate can reduce unsteady spiral dust strand and swirl in cyclone wall. Thus, steady flow of particle can improve classification performance [2]. On top of that, K. W. Chu et al. described that decreasing of particle mass flow rate will cause accumulation and sudden discharging of solids, while increasing of

*Elaine Why: elaine.why1094@gmail.com 
particle loading will achieve steady state of medium flow. This is due to the fact that increase of particle mass flow rate will cause pressure drop and particle tangential velocity to decrease. Hence, steady state airflow will be achieved [3-5]. In addition, effect of air flow rate in dust separation device was done by R. Johansson et al. [6]. Based on the research conducted, they explained that flow and trajectories of fine particles were easier to be affected by turbulence than coarse particles.

Past literatures were mainly focused on the manipulation of solid-gas flow rate, and the effect of particle distribution behaved in the dust separation device. Up to the authors knowledge, no similar research is performed to investigate the coal fineness output in pulverizer of thermal plant. Hence, the methodology of published works are used to apply in this work.

\section{Methodology}

The overall research is carried out in four main phases. Firstly, the coal fineness data is acquired from plant by sieving method. Next, the simulation model is generated by using designing software of PTC Creo Parametric. Grid independence test and numerical simulation works on the model are done by using software of ANSYS Fluent 16.0. Lastly, analysis of simulation results is done, by defining the optimum range of solid-gas flow rate.

\subsection{Experimental coal fineness data}

In this research, experimental work of coal fineness test was performed at $1000 \mathrm{MW}$ ultrasupercritical boiler unit, which was operating at coal particle flow rate of $13.52 \mathrm{~kg} / \mathrm{s}$ and primary air flow rate of $27.04 \mathrm{~kg} / \mathrm{s}$. A sample of $50 \mathrm{~g}$ pulverized coal was collected at the outlet chute of pulverizer. The collected sample of coal was then sieved into specific sizes as shown in Table 1. Coal fineness of more than $75 \mu \mathrm{m}$ will be treated as coarse sizes, while fineness of less than $75 \mu \mathrm{m}$ will be treated as fine sizes.

Table 1. Coal fineness data.

\begin{tabular}{|c|c|c|}
\hline Coal Fineness & Sampling Mass (g) & Percentage (\%) \\
\hline$>300 \mu \mathrm{m}$ & 0.46 & 0.92 \\
\hline$>150 \mu \mathrm{m}$ and $<300 \mu \mathrm{m}$ & 5.85 & 11.70 \\
\hline$>75 \mu \mathrm{m}$ and $<150 \mu \mathrm{m}$ & 11.80 & 23.60 \\
\hline$<75 \mu \mathrm{m}$ & 31.89 & 63.78 \\
\hline Total & 50.00 & 100.00 \\
\hline
\end{tabular}

\subsection{Simulation model development}

The geometric modelling of coal pulverizer model is simplified, by just considering the critical parts such air inlet, coal outlet, classifier and rotating bowl. Such simplification is made in order to minimize computational effort during simulation process. It was also 
anticipated that the absence of minor parts in the flow domain would not affect the accuracy in predicting coal fineness exiting the classifier. Fig. 1 (a) shows the schematic diagram of coal pulverizer model which is developed by using CAD software. The boundary conditions applied in pulverizer models consist of two inlets and one outlet as described in Fig. 1 (b). In this work, coal is assumed to be grinded into a specified range of size and to be released from the surface of rotating bowl. Primary air enters from the air inlet to convey the coal particle from rotating bowl, and exits the coal outlet as phase of solid-gas mixture. The result of coal fineness output is obtained at this point.

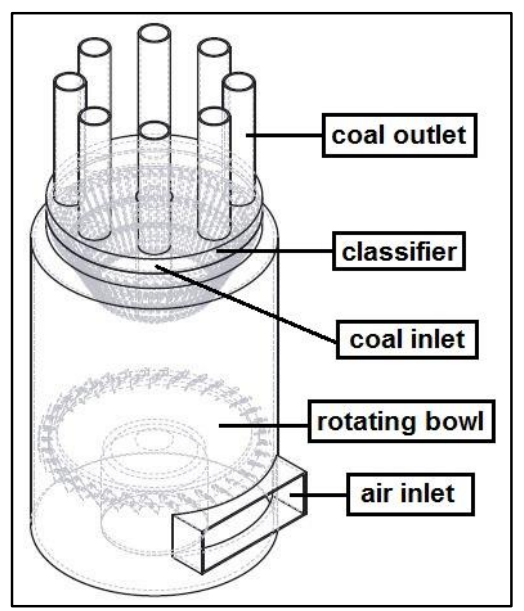

(a)

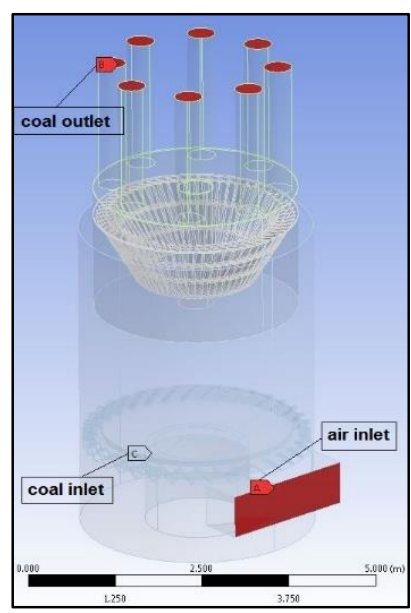

(b)

Fig. 1. Schematic diagram of: (a) simulation model; (b) boundary condition defined.

\subsection{Simulation of model}

Before conducting CFD simulation, initial grid independence test is done on simulation model by considering single phase air flow condition. The test is done by injecting air with velocity of $16 \mathrm{~m} / \mathrm{s}$ perpendicularly at surface of air inlet boundary. Output value of air velocity is obtained at surface boundary of coal outlet in average. The test is conducted by utilizing nine different meshes of tetrahedral cells. The results of this study are summarized as shown in Table 2. The table shows almost consistence output value of air velocity magnitude between 4 million to 10 million number of cells. Therefore, it can be concluded that meshing of cells within this range of number would not affect much on result accuracy. Hence, the minimum cell number of 4 million is used to mesh the simulation model.

Table 2. Result of grid independence test of single phase air flow.

\begin{tabular}{|c|c|c|c|c|c|c|c|c|c|}
\hline Cell Number (million) & $\mathbf{2}$ & $\mathbf{3}$ & $\mathbf{4}$ & $\mathbf{5}$ & $\mathbf{6}$ & $\mathbf{7}$ & $\mathbf{8}$ & $\mathbf{9}$ & $\mathbf{1 0}$ \\
\hline Velocity Magnitude (m/s) & 5.85 & 5.56 & 5.56 & 5.56 & 5.55 & 5.56 & 5.55 & 5.56 & 5.55 \\
\hline
\end{tabular}

Simulation work of this research is then proceeded, by considering solid-gas two phase flow. Several assumptions are also made in simulation, in order to balance out the computational effort and time consumption for simulation results to be obtained. Static classifier is referred in this work and the simulation model is assumed to be solved in case of steady state incompressible flow. Coal is set to be injected perpendicularly upwards from surface of bowl hub, by including Discrete Phase Model (DPM) and Rosin-Rammler 
distribution function to specify particle size $(25-300 \mu \mathrm{m})$. Particle-particle interaction and gravity force are considered in the simulation work, due to high ratio of particle to gas density. Turbulence closure model of Realizable k- $\varepsilon$ is used to solve RANS continuity and momentum equations. The simulation settings and procedure are done repetitively for all cases at different solid-gas flow rate. Table 3 shows the range of input values set for respective parameters, which are $50 \%, 75 \%, 100 \%, 150 \%$ and $200 \%$ of their initial value set in the actual plant manual.

Table 3. Input values of controlling parameters.

\begin{tabular}{|c|c|c|c|c|c|}
\hline Controlling parameter & \multicolumn{5}{|c|}{ Mass flow rate (kg/s) } \\
\hline Input air & 18.03 & 27.04 & 36.05 & 54.08 & 72.11 \\
\hline Input coal particle & 9.01 & 18.03 & 21.63 & 27.04 & 36.05 \\
\hline
\end{tabular}

\section{Results and discussion}

\subsection{Validation of preliminary result with plant data}

In order to ensure the relevancy of assumption made in the simulation settings, it is important to validate simulation result of same case (same solid-gas flow rate) with experimental data. Coal fineness result for case of simulation is obtained as illustrated in Fig. 2, and the particle track is shown by colored particle with different diameter $(\mathrm{m})$. The simulation is able to track minimum particle size of $25 \mu \mathrm{m}$ and up to maximum size of $203 \mu \mathrm{m}$. In simulation, the particles of all sizes are released from surface of bowl hub. When the flow domain reached the classifier section, it is observed that only high portion of fine coal particle sizes between $25 \mu \mathrm{m}$ and $150 \mu \mathrm{m}$ are able to pass through and exited at coal outlet. In general, the simulated model is able to classify $61.50 \%$ of fine coal particle passing $75 \mu \mathrm{m}$ sieve. Summary and comparison of the coal fineness data obtained from both experimental and simulation are as shown in Table 4.

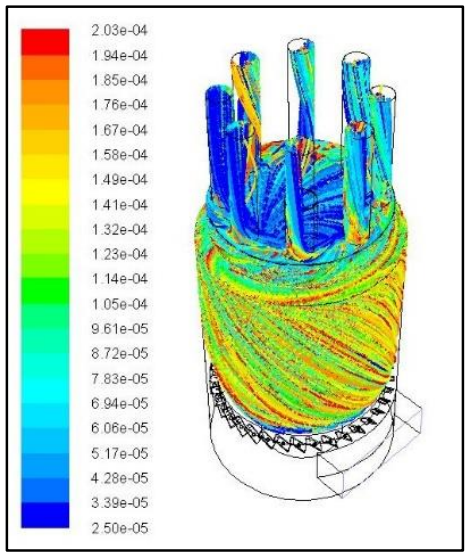

(a)

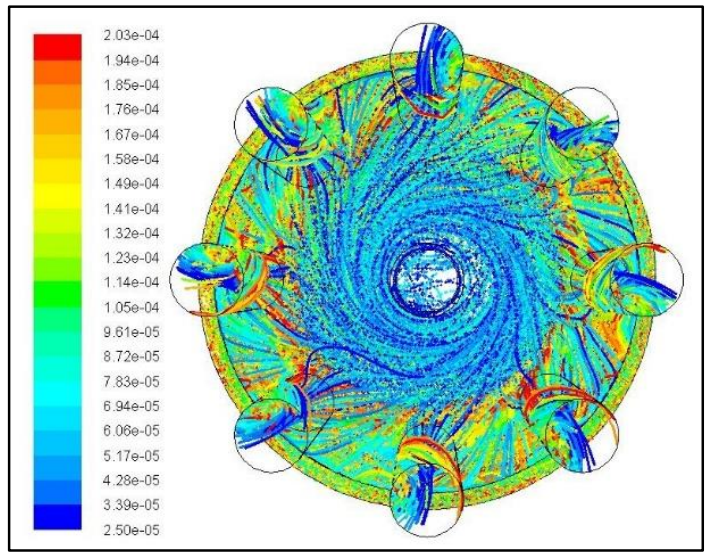

(b)

Fig. 2. Particle track by diameter (m) in simulation model: (a) multi view; (b) top view. 
Table 4. Summary of coal fineness results of experimental and simulation.

\begin{tabular}{|c|c|c|c|}
\hline $\begin{array}{c}\text { Particle diameter } \\
(\boldsymbol{\mu} \mathbf{m})\end{array}$ & $\begin{array}{c}\text { Experimental } \\
\mathbf{( \% )}\end{array}$ & $\begin{array}{c}\text { Simulation } \\
\mathbf{( \% )}\end{array}$ & $\begin{array}{c}\text { Deviation } \\
\mathbf{( \% )}\end{array}$ \\
\hline$>75$ (coarse) & 36.22 & 38.50 & 5.92 \\
\hline$<75$ (fine) & 63.78 & 61.50 & 3.57 \\
\hline
\end{tabular}

As seen from Table 4, deviation between data of experimental and simulation are calculated. Close matches are obtained for this set of result with less than $10 \%$ deviation. The minor deviation occurred in this set of data might due to the assumption of equal particle distribution from bowl hub surface in simulation, imitating particle after grinding process in actual case. In practice, separation of coal may not be ideal, due to some misplacement of coal particles to underflow, which is affected by particle-particle interaction and system instability. Besides, deviation of results might also due to uncertainty in measurement of coal fineness in actual case. Hence, validity of this section of work is agreed by referring to fine coal particle size output, with small deviations.

\subsection{Simulation results}

\subsubsection{Effect of air flow rate on coal fineness output}

This section of simulation is done by manipulating five different air flow values, and keeping constant particle flow rate at $13.52 \mathrm{~kg} / \mathrm{s}$. Fig. 3 summarizes and compares the coal particle diameter distribution at coal outlet of pulverizer model with different air mass flow rate. It can be seen that minimum air flow rate at $18.03 \mathrm{~kg} / \mathrm{s}$ shows to have the lowest output of coal fineness $(<75 \mu \mathrm{m})$ of $60.5 \%$, while maximum air flow rate at $72.11 \mathrm{~kg} / \mathrm{s}$ shows to have the highest output of $63.5 \%$.

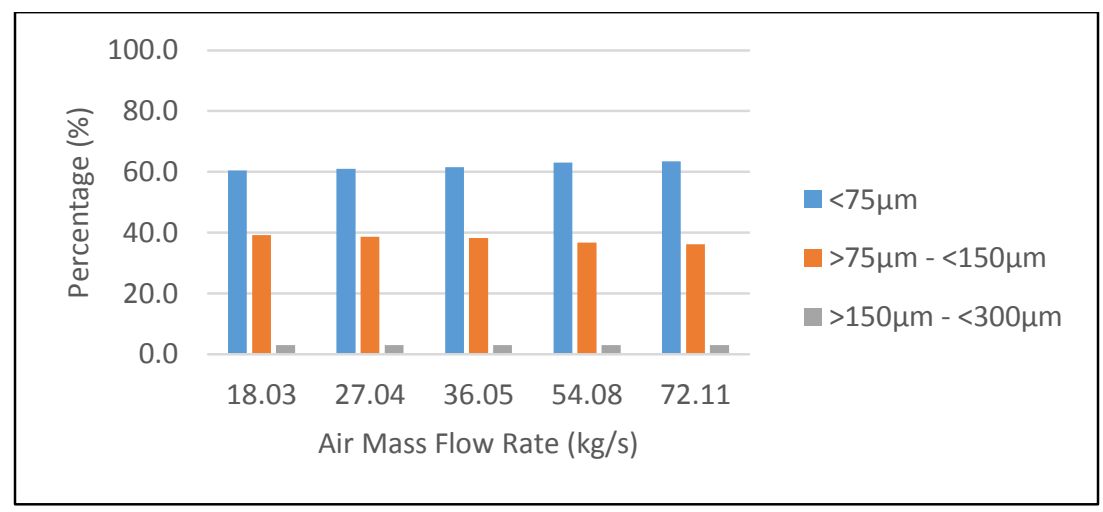

Fig. 3. Comparison of histogram of particle diameter distribution at coal outlet of different air mass flow rate.

In general, the figure shows a proportional increase in coal fineness output as the in feeding air mass flow rate increases. This might due to the fact that, a higher air flow increases the momentum of fine coal particle with higher travelling velocity. However, the coarse coal particle with low momentum and low travelling velocity, have lower possibility to travel 
from bowl hub surface to reach the classifier when compared to fine coal particle. This is also because coarse particle has higher density than fine coal particle, and therefore the upflow motion of coarse coal particle is being highly held back by gravity. Since the output of specified coarse coal particles are limited in this case of air flow, the vacancies in the air phase are then filled in by smaller coal particle in lower density.

\subsubsection{Effect of coal particle flow rate on coal fineness output}

Next, the following simulation is done by manipulating five different particle mass flow values, and keeping constant air flow at $27.04 \mathrm{~kg} / \mathrm{s}$. Fig. 4 summarizes and compares the coal fineness output at different cases of coal particle mass flow rate. Minimum coal particle flow rate at $9.01 \mathrm{~kg} / \mathrm{s}$ is seen to have the highest output of coal fineness of $61.5 \%$. However, model with coal particle flow rate at $27.04 \mathrm{~kg} / \mathrm{s}$ is shown to have the lowest output of coal fineness of $59.0 \%$.

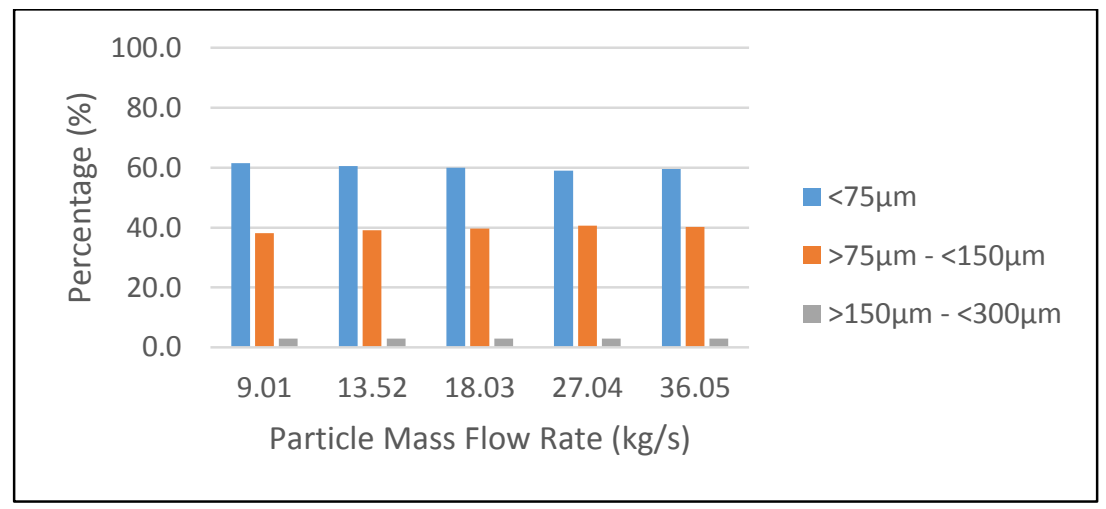

Fig. 4. Comparison of histogram of particle diameter distribution at coal outlet of different coal particle mass flow rate.

As seen in Fig. 4, the decrease in coal fineness output is mainly caused by high input of solid concentration. As high solid concentration residing at the rotating bowl, the total density of coal particle in solid phase is higher than the carrying fluid, causing a high resistance to up warding air flow. The chance for particle-particle collision to generate a large particle-particle interaction force is high, causing the pressure and velocity of in feeding air flow to decrease eventually. Therefore, the total output of fine coal particle is reduced.

\subsubsection{Turbulence intensity and air/fuel ratio}

Besides focusing on the coal fineness output due to different solid-gas flow rate, it is also important to consider both turbulence intensity of solid-gas flow and air/fuel ratio of each cases. In Fig. 5, turbulence intensity at coal outlet shows significant proportional increase to optimization of air and coal particle mass flow rate. However, past studies concluded that high turbulence intensity caused by higher values of air flow rate, will produce higher wall shear stress in the coal channels from pulverizer to boiler for combustion, due to the abrasive force acted by coal particle on the wall surface [7]. Besides, higher flow rate will also affect the balance of air/fuel ratio, as demand of coal increases. Eventually, improper air/fuel ratio will cause higher possibility of incomplete combustion. In this case, implementation of air flow at $72.11 \mathrm{~kg} / \mathrm{s}$ is not encouraged, due to its high value of turbulence intensity which exceeds $100 \%$. 


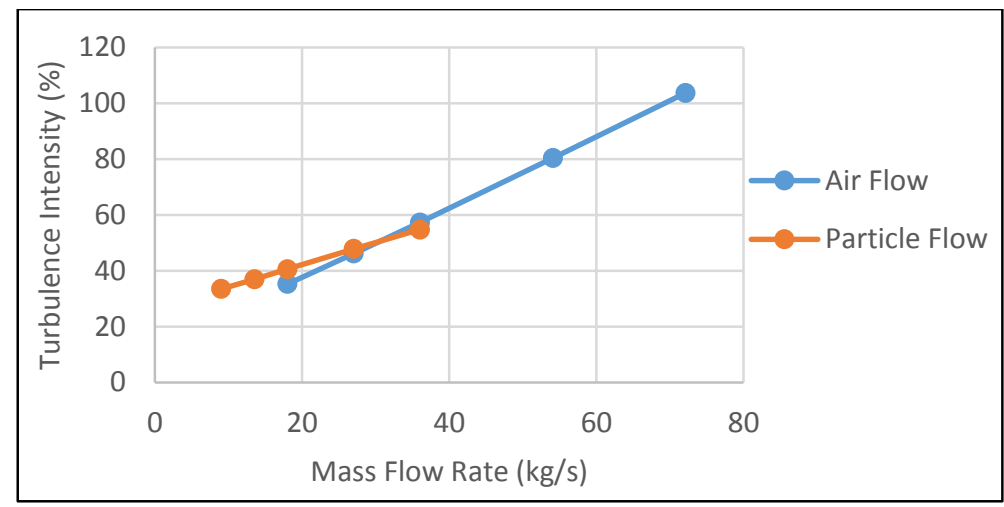

Fig. 5. Turbulence intensity at coal outlet of different air and coal particle mass flow rate.

In addition, Table 5 shows the summary of air/fuel ratio at different cases of solid-gas flow rate. From case 1, it is seen that increasing of air mass flow rate leads to a proportional increase in air/fuel ratio, by keeping the particle flow rate constant. According to previous studies, an optimum air/fuel ratio was suggested to be in the range of 1.5 to 2.0 for adequate coal drying in pulverizer. An air/fuel ratio of lower than 1.0 will result in insufficient coal drying; while ratio of higher than 3.0 will increase the risk of incomplete combustion [8]. Hence, the acceptable range of air flow rate in this case is to be at $18.03-36.05 \mathrm{~kg} / \mathrm{s}$, and keeping at constant coal flow rate of $13.52 \mathrm{~kg} / \mathrm{s}$.

Furthermore, case 2 in Table 5 shows that increasing of coal particle mass flow rate causes a proportional decrease in air/fuel ratio at constant air flow rate. In this case, setting the mass flow rate of coal particle at $27.04 \mathrm{~kg} / \mathrm{s}$ is not encouraged, due to its air/fuel ratio of exact 1.00. This is because most combustion system in practice are preferred to operate under higher air supply than ideal case (air/fuel ratio of 1.00), so that all fuel (coal particle) can be burnt completely. Therefore, the acceptable range of particle flow rate increment in this case is to be at $9.01-21.63 \mathrm{~kg} / \mathrm{s}$, and maintaining at constant air flow rate of $27.04 \mathrm{~kg} / \mathrm{s}$.

Table 5. Summary of air/fuel ratio in cases of different air and particle flow rate.

\begin{tabular}{|c|c|c|c|c|c|}
\hline \multicolumn{7}{|c|}{ Case 1: Air/fuel ratio at different air flow rate } \\
\hline Air flow rate (kg/s) & 18.03 & 27.04 & 36.05 & 54.08 & 72.11 \\
\hline Coal flow rate (kg/s) & 13.52 & 13.52 & 13.52 & 13.52 & 13.52 \\
\hline Air/fuel ratio & 1.33 & 2.00 & 2.67 & 4.00 & 5.33 \\
\hline \multicolumn{7}{|c|}{ Case 2: Air/fuel ratio at different coal particle flow rate } \\
\hline Air flow rate (kg/s) & 27.04 & 27.04 & 27.04 & 27.04 & 27.04 \\
\hline Coal flow rate (kg/s) & 9.01 & 18.03 & 21.63 & 27.04 & 36.05 \\
\hline Air/fuel ratio & 3.00 & 1.50 & 1.25 & 1.00 & 0.75 \\
\hline
\end{tabular}




\section{Conclusion and future work}

CFD modelling is applied to study the effect of coal fineness output, based on manipulation of different mass flow rate of in feeding air and coal particle. Preliminary simulation results are compared with experimental coal fineness test, and validation of data is proved with deviation of less than $10 \%$. The conclusions from the studies can be drawn as following:

- The increasing of air flow rate to the pulverizer results in proportional increase of coal fineness output. The optimum range of air flow rate at $18.03-36.05 \mathrm{~kg} / \mathrm{s}$ is defined, given that coal particle flow rate in pulverizer is kept constant at 13.52 $\mathrm{kg} / \mathrm{s}$.

- The increasing of coal particle flow rate to the pulverizer results in proportional decrease of coal fineness output. The optimum range of coal particle flow rate at $9.01-21.63 \mathrm{~kg} / \mathrm{s}$ is established, with constant flow rate of air at $27.04 \mathrm{~kg} / \mathrm{s}$.

Nonetheless, there are still other factors that can be further analyzed, which are beneficial in achieving complete combustion of coal fuel. The present work can be followed up as such:

- The similar numerical methodology used in this work can be furthered applied in classifier with dynamic effect.

- The design of classifier can be further modelled into other geometrical shapes and blade arrangement, in order to improve the separation efficiency, and achieve higher coal fineness output.

The authors would like to express gratitude to Power Generation Unit, Institute of Power Engineering, Universiti Tenaga Nasional (UNITEN) and Tenaga Nasional Berhad (TNB) for providing research grant to carry out this research.

\section{References}

1. F. B. I. Alnaimi, E. S. K. Why, M. S. Nasif, "Development and implementation of bottom ash crushing system in Submerged Scrapper Conveyor (SSC) for Coal-fired Power Plant," MATEC Web of Conferences, vol. 131, (2017).

2. G. Wan, G. Sun, X. Xue, M. Shi, "Solids concentration simulation of different size particles in a cyclone separator," Powder Technol., vol. 183, no. 1, pp. 94-104, (2008).

3. K. Chu, J. Chen, A. B. Yu, R. A. Williams, "Numerical studies of multiphase flow and separation performance of natural medium cyclones for recovering waste coal," Powder Technol., vol. 314, pp. 532-541, (2017).

4. K. W. Chu, B. Wang, D. L. Xu, Y. X. Chen, A. B. Yu, "CFD-DEM simulation of the gas-solid flow in a cyclone separator," Chem. Eng. Sci., vol. 66, no. 5, pp. 834847, (2011).

5. K. W. Chu, B. Wang, A. B. Yu, A. Vince, "CFD-DEM modelling of multiphase flow in dense medium cyclones," Powder Technol., vol. 193, no. 3, pp. 235-247, (2009).

6. R. Johansson, M. Evertsson, "CFD simulation of a centrifugal air classifier used in the aggregate industry," Miner. Eng., vol. 63, pp. 149-156, (2014).

7. S. K. Thrangaraju, K. M. Munisamy, R. Apparao, "Investigation of flow inside pulverized coal (PC) pipes against coal particle size and air flow rate for a utility boiler," in Journal of Physics: Conference Series, (2017).

8. Storm Technologies Inc., Finessing fuel fineness, pp. 72-76, (2008). 